\title{
Genetic Variation and Population structure: A study on four populations of Tripura, North East India
}

\author{
Priyanka Das ${ }^{1}$, Pranabesh Sarkar' ${ }^{2}$, Diptendu Chatterjee ${ }^{3}$, Arup Ratan Bandyopadhyay ${ }^{4}$ \\ ${ }^{1}$ Research Student, ${ }^{2}$ Senior Research Fellow (UGC-NET), ${ }^{3}$ Assistant Professor, ${ }^{4}$ Professor, Department of Anthropology, \\ University of Calcutta, Technology \& Agriculture, 35, Ballygunge Circular Road, Kolkata - 700019, West Bengal, India
}

Back Ground: Genetic polymorphisms of $\mathrm{ABO}$ and RhD blood group and Haptoglobin (HP) types have already been widely used to understand variation and population structure. The present study attempted to understand the variation and population structure on the basis of $A B O$ and RhD blood group polymorphisms and Haptoglobin (HP) as serum protein polymorphism of four Tibeto-Burman speaker groups considered as aboriginal tribes of Tripura. Genetic studies on populations in north-east Indian have been performed less frequently than in the other parts of India, in spite of diversity among these populations. Aims and Objective: Best of the knowledge the present study is the first attempt on the variation and population genetic structure concerning the $\mathrm{ABO}, \mathrm{RhD}$ and HP polymorphism of the four endogamous populations - Tripuri, Hrangkhawl, Rupini and Kolui tribal population of Tripura. Materials and Methods: Present study consisted of four hundred (400) participants 100 each from above mentioned population groups. ABO and RhD blood groups were done by antigen-antisera agglutination test and HP types were ascertained by Polyacrylamide Gel Electrophoresis (PAGE) following standard techniques. Allele frequencies and Fst were calculated by using standard method. Results: Examination on $\mathrm{ABO}$ blood group revealed higher $\mathrm{O}$ allele among the two groups Tripuri and Hrangkhawl followed by $A$ and $B$ alleles. Among the other two groups, Rupini and Kolui, revealed higher $A$ allele and B allele respectively. Higher D allele frequency in the RHD Blood group system has been found for each of the population group. On the other hand, Serum protein marker - HP types demonstrated higher $\mathrm{HP}^{*} 2$ allele frequency than $\mathrm{HP}^{*} 1$ alleles. Calculated very low Fst value (0.02-0.08) of three polymorphic markers ( $A B O, R h D$ and HP) were suggestive for low differentiation among these groups, indicating less admixture and prevailing endogamous nature of these population. Conclusion: Very low Fst values of three polymorphic markers were suggestive for low differentiation among these groups, indicating least admixture and prevailing endogamous nature of these population. The overall genetic difference revealed highest distance between Tripuri and Hrangkhwal and least distance between Rupini and Kolui.

Key words: ABO, RhD, HP, Tripura, Fst, Genetic difference.
Access this article online

Website:

http://nepjol.info/index.php/AJMS

DOI: 10.3126/ajms.v9i3.19492

E-ISSN: 2091-0576

P-ISSN: $2467-9100$

\section{INTRODUCTION}

Determining the genetic structure of natural populations forms an important part of population genetics. For example, this has applications in evolutionary biology, conservation and forensics. India occupying the centrestage of Palaeolithic and Neolithic migrations, and somewhat has been under-represented in genome-wide studies of variation. ${ }^{1}$ Being at the cross-roads of migration, Indian populations have undergone complex and ancient admixture events over a long period ${ }^{2-5}$ and have been the melting-pot of disparate ancestries originating from different parts of Eurasia and South-East Asia., ${ }^{56}$ Although the date of entry of modern humans into India remains uncertain but it is reasonable to consider by the middle Palaeolithic period (50,000-20,000 years before present ybp), humans appear to have spread to many parts of India. ${ }^{7}$ The contemporary ethnic India is a land of enormous genetic, cultural, and

Address for correspondence:

Arup Ratan Bandyopadhyay, Department of Anthropology, University College of Science, Technology \& Agriculture, 35, Ballygunge Circular Road, Kolkata - 700019, West Bengal, India. Mobile: +91-9432316126. E-mail: abanthro@caluniv.ac.in (C) Copyright AJMS 
linguistic diversity. ${ }^{8-10}$ A more recent study exploring Indian genomic diversity demonstrated four major ancestral genetic components in mainland India that included four dominant ancestries in populations from mainland India: Ancestral North-Indian (ANI), Ancestral South-Indian (ASI), Ancestral Tibeto-Burman (ATB) and Ancestral Austro-Asiatic (AAA). ${ }^{5} \mathrm{On}$ the basis of the literature review on major and contributing publications regarding genetic structure of the North East Indian population, it has been found that studies on the tribal populations of Tripura seems to have been under represented.

In this context, to best of the knowledge, the present study is the first attempt to understand the variation and population structure of the four Tibeto-Burman speaking tribal populations, namely Tripuri, Hrangkhawl, Rupini and Kolui tribal population of Tripura, North East India using the three ABO, RHD and Haptoglobin (HP) polymorphic traits.

\section{MATERIALS AND METHODS}

\section{Background of studied participants}

Tripura, a hilly state in the North-Eastern region of India is the homeland 19 tribal populations. The tribal populations can be divided into two major groups as (i) Ab-original (Tripuri, Reang, Jamatia, Noatia, Lusai, Uchai, Chaimal, Halam, Kukis, Garos, Mog and Chakma) and (ii) Immigrants (Bhil, Munda, Orang, Santal, Lepcha, Khasia, Bhutias). The aboriginal tribal populations of this state have been migrated in this territory from a place in between Tibet, up hills of Burma, like Arakan Hills Tracts and Shan State and adjacent to China. The immigrant tribal populations mostly migrated from their homeland located in the states of Madhya Pradesh, Bihar, Orissa and West Bengal. Some of these tribes are, however, Northern-Frontier tribes who migrated from the states of Bhutan, Meghalaya, Sikkim and North Bengal. The Chakmas and the Mogs are the Arakan Tribes who entered Tripura through the Chittagong Hills Tracts.

Linguistically, the aboriginal tribal populations of the state of Tripura can be divided into three groups, such as Bodo Groups, Kuki-Chin Groups and Arakan Groups. The tribal populations, like Tripuri, Reang, Jamatia, Uchai and Noatias bear Mongoloid physical features and belong to the Bodo linguistic group. The Kukis, Lusai and most of the tribes under Halam tribes linguistically belongs to the Kuki-Chin group and speak in Kuki-Chin language. The Mog and the Chakmas speak in Arakan language. While most of the tribal populations of Tripura follow Hinduism, the Lusai-Kukis embraced Christianity and the Chakmas and Mogs embraced Buddhism. ${ }^{11}$
The present study was carried out among the four endogamous tribal groups, Tripuris, Kolui, Rupini and Hranghawls (sub clan groups of Halam). The area of the study was Kamalasagar and Sipahijola districts of West Tripura. Ethnically, Halam belongs to the Kuki-Chin tribes. Their language is also similar to that of the languages under the Tibeto-Burman family. Halams are also known as Mila Kuki, though they are not at all Kukis in terms of language, culture and living style. Halams are divided into several sub-clans which are referred as "BarkiHalam". The major sub-clans of Halams are (1) Kaloi (2) KorBong (3) Keipeng (4) Bong (5) Saka Chep (6) Thanga chep (7) Dab (8) Bongser (9) Rupini (10) Hrangkhawl (11) Chorai (12) Langai (13) Kaireng (14) Ranglong (15) Naveen and (16) Khulang. The Hrankhawls are one of the sub clans of Halam-Kuki community. On the other hand, Tripuris originated from the Indo-Mongoloid stock and linguistically affiliated to the Tibeto-Burman family. The Tripuris are the largest tribal community and the first group of aboriginal tribal migrants of Tripura.

The study was conducted on 100 participants each from Tripuri, Hrangkhawl, Rupini and Kolui tribal population, and altogether 400 individuals from West Tripura. Prior to the study, verbal consent was taken from each of the participants. Blood samples were collected in EDTA vial and kept in ice buckets and collected samples were transported to the Human Genetics Laboratory, Department of Anthropology, University of Calcutta for further analysis. $\mathrm{ABO}$ and RHD blood phenotypes were obtained by standard antigen-antisera agglutination technique. ${ }^{12}$ Polyacrylamide Gel Electrophoresis (PGE) $(7 \%)$ technique was used to identify the Haptoglobin (HP) phenotypes using standard protocol with slight modification. ${ }^{13}$ The allele frequencies for all the polymorphic markers, such as $\mathrm{ABO}$ and $\mathrm{RHD}$ blood groups including HP were computed by Maximum Likelihood Estimation. ${ }^{14}$ Fst statistic ${ }^{15}$ was calculated to estimate the genetic differentiation of the studied populations. The test of goodness of fit (chi-square test) based on the observed and expected frequencies of polymorphic markers were calculated in order measure Hardy-Weinberg equilibrium and as well the measure of genetic equilibrium $(\mathrm{D} / \sigma)$ was computed to understand the excess or deficiency of AB blood group. The overall genetic difference $\left(G^{2}\right)$ between any two endogamous groups was calculated ${ }^{16,17}$ using standard procedure. The cut off was set as $\mathrm{p}=0.05$.

\section{RESULTS AND DISCUSSION}

Distribution of phenotypes and allele frequencies of $A B O$ blood group as presented in Table-1, demonstrated higher $\mathrm{O}$ allele among the two groups Tripuri and Hrangkhawl followed by A and B alleles. Among the other two groups, Rupini and Kolui, revealed higher A allele and B allele 
respectively. Estimated Hardy-Weinberg (HW) equilibrium revealed no deviation for $\mathrm{ABO}$ allele frequencies among the four groups. Moreover, the four groups showed significant $\left(\mathrm{Chi}^{2}=94.44 ; 9 \mathrm{df} ; \mathrm{p}<0.05\right)$ difference in the distribution of $\mathrm{ABO}$ blood group phenotypes. The computed positive values of genetic equilibrium $(\mathrm{D} / \sigma)$ for all these groups indicated no as such deficiency of $\mathrm{AB}$ blood group. The distribution of $\mathrm{ABO}$ blood group and allele frequencies with higher A blood group than other regions of India and close $A$ and $B$ allele frequency of the four Tibeto-Burman speaker groups was found to be in consistency with earlier studies. ${ }^{18-20}$

Examination on Rh blood group phenotypes (Table 2) revealed highest proportion of $\mathrm{D}$ alleles and also found to be in HW equilibrium for all the groups. Comparative distribution of Rh blood group phenotypes between the four groups demonstrated significant $\left(\mathrm{Ch}^{2}=24.67 ; 3 \mathrm{df} ; \mathrm{p}<0.05\right)$ differences. The distribution of higher frequency of $\mathrm{RhD}$ alleles among these Tibeto-Burman speaker groups was found to be in corroboration with earlier studies. ${ }^{18-20}$ Estimated allele frequencies (Table 3) of serum protein marker (HP) revealed higher HP*2 alleles in all the four groups. Rupini, Kolui, Tripuri, demonstrated no significant deviation from HW equilibrium, while Hrangkhawl showed significant $\left(\mathrm{Chi}^{2}=15.34\right.$; $1 \mathrm{df} ; \mathrm{p}<0.05)$ deviation from HW equilibrium. Furthermore, significant $\left(\mathrm{Chi}^{2}=69.59 ; 6 \mathrm{df} ; \mathrm{p}<0.05\right)$ difference between these four groups in terms of the distribution of haptoglobin phenotypes were evident. However, the result of the present study in terms of higher frequency of HP*1 alleles in comparison to other linguistic groups (except Indo-European) confirms the consistency with the earlier studies. ${ }^{18-20}$ The estimated Fst values for three genetic marker traits of the four populations (Table 1, 2 and 3) demonstrated very low values (Range 0.02-0.08), indicating low differentiation ${ }^{21}$ among these four ethnic (aboriginal) groups of Tripura. Furthermore, the low values of Fst also signify higher possibility of endogamy among these populations.

Genetic differences as calculated by $\mathrm{G}^{2}$ analysis ${ }^{16,17}$ revealed (Table 4) highest distance between Tripuri and Hranghwal and least distance between Rupini and Kolui. Probable population Structure revealed both Rupinis and Koluis closer to the Tripuris, and Rupinis and Koluis are very close to each other. The available result from the present study indicated the possibility of the origin of Rupini and Kolui group from the major aboriginal group Tripuri.

The result of the present study corroborates with the earlier studies conducted on Tibeto Burman speakers of Tripura in terms of low differentiation ${ }^{22-24}$ and high homogeneity on Haplogroups. The overall result obtained from the present attempt delineates higher possibility of endogamy

Table 1. Distribution of ABO blood group phenotypes and allele frequencies among the four studied population

\begin{tabular}{|c|c|c|c|c|c|c|c|c|c|c|}
\hline \multirow[t]{2}{*}{ Population } & \multirow[t]{2}{*}{$(\mathrm{N})$} & \multicolumn{4}{|c|}{ Blood group, (\%) } & \multicolumn{3}{|c|}{ Allele frequencies } & \multirow[t]{2}{*}{$\mathrm{Chi}^{2} \mathrm{df}=3$} & \multirow[t]{2}{*}{ Fst } \\
\hline & & A & B & 0 & $A B$ & A & B & 0 & & \\
\hline Rupini & 100 & $38(38.00)$ & $37(37.00)$ & $6(6.00)$ & $19(19.00)$ & 0.357 & 0.348 & 0.288 & 3.4 & 0.08 \\
\hline Kolui & 100 & $25(25.00)$ & $55(55.00)$ & $5(5.00)$ & $15(15.00)$ & 0.237 & 0.475 & 0.285 & 6.26 & \\
\hline Tripuri & 100 & $36(36.00)$ & $24(24.00)$ & $37(37.00)$ & $3(3.00)$ & 0.221 & 0.148 & 0.629 & 2.91 & \\
\hline Hrangkhawl & 100 & 37 (37.00) & $22(22.00)$ & 39 (39.00) & $2(2.00)$ & 0.221 & 0.130 & 0.640 & 3.71 & \\
\hline
\end{tabular}

Table 2. Distribution of RHD blood group phenotypes and allele frequencies among the four studied population

\begin{tabular}{|c|c|c|c|c|c|c|c|}
\hline \multirow[t]{2}{*}{ Population } & \multirow[t]{2}{*}{$(\mathrm{N})$} & \multicolumn{2}{|c|}{ Blood groups, (\%) } & \multicolumn{2}{|c|}{ Allele frequencies } & \multirow[t]{2}{*}{$\mathrm{Chi}^{2} 1 \mathrm{df}$} & \multirow[t]{2}{*}{ Fst } \\
\hline & & Rh D & Rh d & D & d & & \\
\hline Rupini & 100 & $99(99.00)$ & $1(1.00)$ & 0.99 & 0.01 & 0.000 & 0.02 \\
\hline Kolui & 100 & $95(95.00)$ & $5(5.00)$ & 0.78 & 0.22 & 0.006 & \\
\hline Tripuri & 100 & $86(86.00)$ & $14(14.00)$ & 0.63 & 0.37 & 0.008 & \\
\hline Hrangkhawl & 100 & $80(80.00)$ & $20(20.00)$ & 0.56 & 0.44 & 0.020 & \\
\hline
\end{tabular}

Table 3. Distribution of haptoglobin phenotypes and allele frequencies among the four studied population

\begin{tabular}{|c|c|c|c|c|c|c|c|c|}
\hline \multirow[t]{2}{*}{ Population } & \multirow[t]{2}{*}{$(\mathrm{N})$} & \multicolumn{3}{|c|}{ Haptoglobin group, (\%) } & \multicolumn{2}{|c|}{ Allele frequencies } & \multirow[t]{2}{*}{$\mathrm{Chi}^{2} \mathrm{df}=2$} & \multirow[t]{2}{*}{ Fst } \\
\hline & & Hр 1-1 & Hp 2-1 & Hр 1-1 & Hp 1 & Hp 2 & & \\
\hline Rupini & 100 & $1(1.00)$ & $14(14.00)$ & $85(85.00)$ & 0.08 & 0.92 & 0.51 & 0.06 \\
\hline Kolui & 100 & $1(1.00)$ & $25(25.00)$ & $74(75.00)$ & 0.13 & 0.87 & 2.26 & \\
\hline Tripuri & 100 & $6(6.00)$ & $51(51.00)$ & $43(43.00)$ & 0.31 & 0.68 & 3.43 & \\
\hline Hrangkhawl & 100 & $1(1.00)$ & $59(59.00)$ & $40(40.00)$ & 0.30 & 0.70 & 15.34 & \\
\hline
\end{tabular}




\begin{tabular}{|c|c|}
\hline & $\begin{array}{c}\text { Genetic difference }\left(G^{2}\right) \\
\text { (Sanghvi and Khanolkar, 1949; } \\
\text { Sanghvi, 1953) }\end{array}$ \\
\hline Rupini - Kolui & 0.0001 \\
\hline Rupini - Tripuri & 0.0049 \\
\hline Rupini - Hrangkhawl & 0.0043 \\
\hline Kolui - Tripuri & 0.0018 \\
\hline Kolui - Hrangkhawl & 0.0032 \\
\hline Tripuri - Hrangkhawl & 0.0056 \\
\hline
\end{tabular}

among the studied four groups (Tibeto- Burman speakers) of North East India from Tripura and thus indicating no admixtures among these Tibeto Burman speaker groups.

\section{ACKNOWLEDGEMENTS}

Financial support from University of Calcutta [BI $65(8 \& 9)$ is acknowledged. Authors are grateful to the participants for their kind cooperation

\section{REFERENCES}

1. Cann RL. Genetic clues to dispersal in human populations: retracing the past from the present. Science 2001; 291:1742-1748.

2. Bamshad MT, Kivisild,WS, Watkins, ME, Dixon CE, Ricker, BB, Naidu JM, et al. Genetic evidence on the origins of Indian caste populations. Genome Research 2001; 11:994-1004.

3. Reich D, Thangaraj K, Patterson N, Price AL and Singh L. Reconstructing Indian population history. Nature 2009; 461:489-494.

4. Moorjani P, Thangaraj K, Patterson N, Lipson M, Loh PR, Govindaraj $P$, et al. Genetic evidence for recent population mixture in India. American Journal of Human Genetics 2013; 93: 422-438.

5. Basu, A. Sarkar-Roy, N. and Majumder, PP. Genomic reconstruction of the history of extant populations of India reveals five distinct ancestral components and a complex structure. Proceedings of National Academy of Science 2016; 113: 201513197.

6. Basu A, Mukherjee N, Roy S, Sengupta S, Banerjee S, Chakraborty M, et al. Ethnic India: A Genomic View, With Special Reference to Peopling and Structure. Genome Research 2003; 13:2277-2290.

7. Misra VN. Stone Age in India: An ecological perspective. Man and Environment 1992; 14: 17-64.
8. Karve I. Hindu Society: An interpretation. 1961. Deshmukh Prakashan, Poona, India

9. Majumder PP. People of India: Biological diversity and affinities. Evolutionary Anthropology 1998; 6: 100-110.

10. Roychoudhury S, Roy S, Dey B, Chakraborty M, Roy M, Roy B, et al. Fundamental genomic unity of ethnic India is revealed by analysis of mitochondrial DNA. Current Science 2000; 79: 1182-1192.

11. http://www.tritripura.in/tri/Tribes/Index.aspx (accessed on March 21, 2018).

12. Daniels G. Human Blood Groups. 2002; $2^{\text {nd }}$ edition, Blackwell Science. UK

13. Hasan $M$, Mohiledin A, Alzohairy $M$ and Khan $M$. Human haptoglobin phenotypes on native- page using tetramethylphenylenediamine (TMPD) Staining. International Journal Of Biological and Medical Research 2012; 3: 1342-1344.

14. Cavalli-Sforza LL and Bodmer WF. The Genetics of Human Populations 1971; W.H Freeman and Company, San Francisco.

15. Weir BS and Cockerham C. Estimating F-statistics for the analysis of population structure. Evolution 1984; 38: 1358-1370.

16. Sanghvi LD and Khanolkar VR. Data relating to seven genetical characters in six endogamous groups in Bombay. Annals of Eugenics 1949; 15: 52-76.

17. Sanghvi LD. Comparison of genetical and morphological methods for a study of biological differences. American Journal of Physical Anthropology 1953; 11: 385-404.

18. Walter $\mathrm{H}$, Danker-Hopfe $\mathrm{H}$ and Bhasin MK. Anthropologie Indiens. Untersuchungen zur genetischen Variabilität der Bevölkerung Indiens mit besonderer Berücksichtigung ihrer regionalen, ethnosozialen und sprachlichen Gliederung. 1991; Stuttgart, New York Gustav Fischer.

19. Bhasin MK, Walter H and Danker-Hopfe H. People of India: An Investigation of Biological Variability in Ecological, Ethno-economic and Linguistic Groups. 1994; Delhi, Kamla-Raj Enterprises.

20. Meiti YS, Asghar M, Achoubi DN, Murry B, Saraswathy $N$ $K$ and Sachdeva $P$ M. Distribution of $A B O$ and $R h(D)$ blood groups among four populations in Manipur, North-East India. Anthropological Notebooks 2010; 16:19-28.

21. Hartl DL and Clark AG. Principles of Population Genetics 1997; $3^{\text {rd }}$ edition, Sinauer Assoc., Sunderland, MA, USA.

22. Ghosh T, Kalpana D, Mukerjee S, Mukherjee M, Sharma A K, Nath $S$, et al. Genetic diversity of autosomal STRs in eleven populations of India. Forensic Science International: Genetics 2011; 5:259-261.

23. Sengupta S, Zhivotovsky LA, King R, Mehdi SQ, Christopher AE, Cheryl-Emiliane $\mathrm{C}$, et al. Polarity and Temporality of HighResolution Y-Chromosome Distributions in India Identify Both Indigenous and Exogenous Expansions and Reveal Minor Genetic Influence of Central Asian Pastoralists. American Journal of Human Genetics 2006; 78: 202-221.

24. Sarkar P, Dutta P, Chatterjee D and Bandyopadhyay AR. Genetic Variation and Population structure: A study on the Tipuris and Hrangkhawls of Tripura. Journal of Indian Anthropological Society (In Press).

\section{Authors Contribution:}

PD- Collected Data, laboratory analysis, statistically analyzed; PS- laboratory analysis, statistically analyzed DC- reviewed the literature, helped in preparing first draft of manuscript; ARB- Concept and design of the study, data interpretation, critical revision of the manuscript

Work attributed to:

Department of Anthropology, University of Calcutta, Kolkata

Orcid ID:

Prof. Arup Ratan Bandyopadhyay- ㄴ http://orcid.org/0000-0003-3119-0022

Source of Support: University of Calcutta [BI 65 (8 \&9)], Conflict of Interest: None declared. 